\title{
The unified approach of radiation on biological matter: Action of sparsely ionizing
}

\section{radiation on mammalian cells}

\author{
Ali Salem Alkharam * \\ Department of Physics, Faculty of Science, University of Benghazi, Benghazi, Libya.
}

Global Journal of Engineering and Technology Advances, 2022, 10(02), 075-082

Publication history: Received on 03 December 2021; revised on 22 February 2022; accepted on 24 February 2022

Article DOI: https://doi.org/10.30574/gjeta.2022.10.2.0160

\begin{abstract}
Using a wide range of published data from irradiation experiments by sparsely ionizing radiation over mammalian cells, a tangible relationship between the cellular damage; effect cross-section and radiation quality represented the spacing between ionizing events over the path of generated primary electrons; the mean free path for linear primary ionization. The maximum damage by sparsely ionizing radiation can only be established by ultra-soft $\mathrm{x}$-rays from $\mathrm{C}(\mathrm{k})$ where the mean free path along the track of the cell nucleus is about $2 \mathrm{~nm}$. At higher mean free path, other ultra-soft and soft xrays become potentially harmful only with the contribution of water radicals. A simple semi-theoretical model is proposed to define absolute biological effectiveness based on effect inactivation cross section which is interrelated to the mean free path for linear primary ionization. For sparsely ionizing radiation, the model shows a feasible saturation region for the effect cross-section $5 \mu^{2}$ for mean free path less than $1.8 \mathrm{~nm}$. The model explains the mechanisms leading to cell death via DNA strand scissions. The effect of sparsely ionizing radiation contributes only to a fraction of $(1 / 20)$ of the maximum reachable damage.
\end{abstract}

Keywords: Effect cross-sections; Mean free path; Mammalian cells; Sparsely ionizing radiation; Biophysical modelling

\section{Introduction}

Although heavy charged particles (termed as densely ionizing radiation; DIR) have its own advantages over conventional $\mathrm{x}$-ray, $\gamma$-ray and electron beams (termed as sparsely ionizing radiation; SIR) in the therapeutic treatments, especially for deep situated tumors, SIR are still important in other areas of medical sciences including radiography, mammography computer tomography and even therapeutic treatments [1]. Depending on their energy, photons propagate through matter and interact with its atomic electrons. For energies up to $100 \mathrm{keV}$, the photon is completely absorbed by the atomic electron via photo-electric effect. At energies up to few $\mathrm{MeV}$, Compton scattering becomes the predominant interaction, where the photon gives up part of its energy to the electron. With higher energies up, pairproduction will be more important. In all processes, primary electrons are produced. The fate of these free electrons inside biological matter is decided by their kinetic energy. They lose energy through ionizations and excitations events while slowing down in biological matter. The average energy lost per ionization along the electron track in water is within the range of $22-26 \mathrm{eV}$ [2]. The average distance between successive ionization is longer, for higher energy electrons and deceases as the electron slows down. As whole, primary electrons produce sparse ionization tracks as compared to dense tracks produced by heavy charged particles like protons or other heavier charged ions. Different radiation qualities such as track Linear Energy Transfer (LET) and the mean free path for linear primary ionization (MFP; $\lambda$ ) can be characterized by the ionisation density. LET is defined as the mean energy deposited per track length and is measured in $(\mathrm{keV} / \mu \mathrm{m})$, while MFP represents the mean spacing distance between two consecutive ionizations along the primary track measured in (nm) [3-4]. Unlike DIR which are characterized by their high LET values, SIR identified by their lower LET values. LET of x-rays with values $0.1-20 \mathrm{keV} / \mu \mathrm{m}$ depend on $\mathrm{x}$-rays spectrum, which is

\footnotetext{
${ }^{*}$ Corresponding author: Ali Salem Alkharam
}

Department of Physics, Faculty of Science, University of Benghazi Benghazi, Libya.

Copyright $@ 2022$ Author(s) retain the copyright of this article. This article is published under the terms of the Creative Commons Attribution Liscense 4.0. 
determined by a combination of three factors, the x-ray tube anode material, the x-ray beam filtration material and the high operational voltage (KV). LET for $\gamma$-rays is about $0.5-1 . \mathrm{KeV} / \mu \mathrm{m}$ [5 - 6]. LET of high energy photons produced in linear accelerators varies between $0.15-4.5 \mathrm{keV} / \mu \mathrm{m}$ for electron energies varies between $50-4 \mathrm{MeV}$. These LET values are substantially low as compared with heavy charged particles LET, i.e. for $4 \mathrm{MeV} \alpha$-particles, LET is about 100 $\mathrm{KeV} / \mu \mathrm{m}$.

Deoxyribonucleic acid (DNA) is widely accepted as the vital target for the induction of cell killing by ionizing radiation. Upon their interaction with DNA molecules, ionizing radiations produce a variety of damages, including double-strand breaks (dsb's), single-strand breaks (ssb's) and base damages, as presented in Figure-1 a. Due to their high ionization density, DIR interact directly with DNA molecules to induce adjacent DNA breaks forming what is known as dsb's. On the other hand, Photons and energetic electrons interact with DNA molecules either directly with lower probability, or indirectly via ionization of water molecules with higher probability (as compared to DIR) to generate a spectrum of lesions, of which base damage and ssb's are the most abundant [7]. The enhancing role of water radicals produced by SIR interactions with water to damage the DNA is shown in Figure-1b. In the last few decades, researchers have provided evidences that the double breaks of DNA opposite strands are responsible for cell death [8-11].

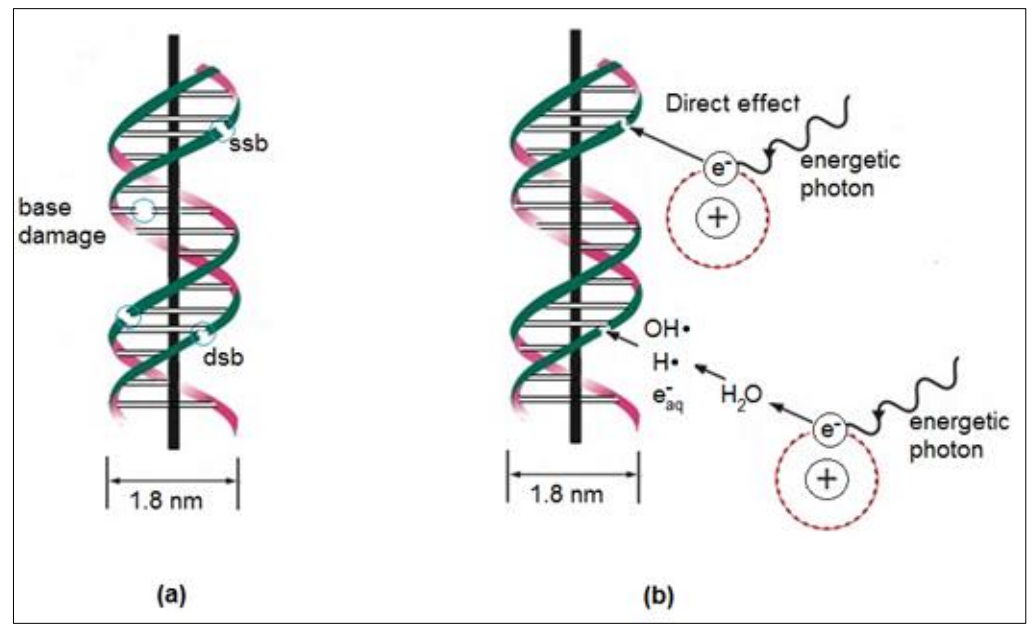

Figure 1 (a) Schematic representations of selected types of ionizing radiation damage to the DNA; ssb, dsb (two adjacent ssb's) and base damage. (b) Direct and indirect damage by SIR to the DNA where free radicals $(\mathrm{OH}, \mathrm{H} \bigcirc$ or hydrated electron formed by the water hydrolysis; the radicals then diffuse to damage the DNA by chemical reaction

The correlation between biological effects and a suitable physical parameter led to propositions of many biophysical models [12-14]. While the main objective of each model is to predict the shortage of experimental outcomes, it is also providing a deeper insight of the damage mechanisms at cellular level [15-17]. Watt and his group suggested that the spacing of ionizing events along primary charged particle tracks can explain the details of the different mechanisms at nanometric scales in terms of MFP for linear primary ionization [18].

Cell death is commonly considered as a reference endpoint to characterize the action of ionizing radiation in different subcellular targets. It is also the goal for any tumor therapy. With this respect, radiobiological experiments involving in vitro exposure of mammalian cells to different types of SIR, still provide a useful source of information. The damaging effect of what is known as reproductive death as an end point presented by survival curves; where fraction of survival usually on logarithmic scale, against radiation dose in linear scale. The shape of the curve depends on radiation type and to a certain extent on Eukaryotic cells type. In general SIR such as x-rays, and fast electrons have shoulder type of curve, while heavy charged particles such as protons, alpha particles have linear response type. It is useful to make use of linear quadratic fitting formula;

$$
F(S)=\ln (S / \text { So })=-\alpha D-\beta D^{2},
$$

where $\alpha\left(\mathrm{Gy}^{-1}\right), \beta\left(\mathrm{Gy}^{-2}\right)$ are constant parameters for any specific curve. The first term represent the slope of survival curve at zero dose, which is also known as the radio sensitivity parameter. For linear survival curve; $\beta=0$, and the equations becomes simply as $F(S)=\ln (S /$ So $)=-\alpha D$.

The present study will focus on physical parameterization of the biological damage caused by different ionizing radiations. Hence presenting a model that unifies the action of SIR on mammalian cells. 


\section{Method of Approach}

It is far much better to quantify the cellular damage induced by ionizing radiation in terms of the probability of producing damage in units of area, inactivation cross section; $\sigma_{\mathrm{s}}\left(\mu \mathrm{m}^{2}\right)$ Inactivation cross sections $\sigma_{\mathrm{s}}\left(\right.$ in $\left.\mu \mathrm{m}^{2}\right)$ of a variety of mammalian cells were calculated using the relation:

$$
\sigma_{s}=\frac{L_{T}}{6.25 \rho D_{o}}
$$

Where $\mathrm{L}_{\mathrm{T}}$ is the track average LET (in $\mathrm{keV} / \mu \mathrm{m}$ ) for the equilibrium spectrum of charged particles involved, $D_{o}$ (in Gy), and $\mathrm{P}$ (in $\mathrm{gm} / \mathrm{cm}^{3}$ ) is the density of biological matter. Cross sections were determined for the initial slope of survival curves to avoid any problems associated with cell recovery. The initial slope for cell survival curve is simply the slope of curve at zero dose. For both survival curves whether shouldered or linear types, the initial slope is equivalent to $\alpha$. Hence the inactivation cross section is evaluated at $D_{o}=1 / \alpha$. For wet cells, the density of medium is assumed of water.

The cell survival radio-sensitivity parameter $\alpha\left(\mathrm{Gy}^{-1}\right)$ for mammalian cell lines by the various SIR were extracted from published data [19-41]. The present study include mammalian inactivation data caused by SIR of different qualities; ultra-soft and ( $0.277 \mathrm{keV} \mathrm{C}_{\mathrm{k}}, 1.456 \mathrm{keV} \mathrm{Al}$, $4.51 \mathrm{keV} \mathrm{Ti}$, and $\mathrm{Cr}_{\mathrm{k}} 5.4 \mathrm{keV}$ ), soft x-rays (10 KVp - $\left.40 \mathrm{KVp}\right)$, medium hard $\mathrm{x}$-rays (50 KVp - $110 \mathrm{KVp}$ ), hard x-rays (varied $120 \mathrm{kVp}-300 \mathrm{kVp}$ ), very hard x-rays (4 MV - $50 \mathrm{MV}$ ), ${ }^{60} \mathrm{Co},{ }^{137} \mathrm{Cs} \gamma$-rays, and energetic electrons $(\sim 1 \mathrm{MeV}$ and $18 \mathrm{keV})$, as tabulated in table-1 below. The track average structure parameters; Average energy of electrons emitted assumed to be emitted from a radiator source; $\mathrm{E}_{\mathrm{s}}(\mathrm{keV})$, the average $\mathrm{LET}(\mathrm{keV} / \mu \mathrm{m})$ and $\lambda(\mathrm{nm})$ ), are all estimated using Watt's group foundations [42]. Here the average values are calculated for the electron equilibrium spectrum. The corresponding cross sections $\sigma\left(\mu \mathrm{m}^{2}\right)$ were estimated using the above formula and the results are tabulated in Table-1.

Table 1 SIR track structure data; $E_{s}(\mathrm{keV})$, LET $(\mathrm{keV} / \mathrm{mm})$, and $\lambda(\mathrm{nm})$ along with radio-sensitivity parameter $\alpha\left(\mathrm{Gy}{ }^{-1}\right)$; $E_{s}$ is the average energy of electrons produced by photons (or electron) interactions

\begin{tabular}{|c|c|c|c|c|c|c|c|}
\hline No. & Source/Type & $\mathrm{E}_{s}(\mathrm{keV})^{*}$ & LET $(\mathrm{keV} / \mu \mathrm{m})$ & $\alpha\left(G y^{-1}\right)$ & $\lambda(\mathrm{nm})$ & $\sigma_{s}\left(\mu m^{2}\right)$ & Reference \\
\hline 1 & $0.277 \mathrm{keV} \mathrm{C}(\mathrm{K}) \mathrm{X}$-rays & 0.1202 & 18.34 & 0.6220 & 2.45 & 1.8252 & Goohead, 1980 \\
\hline 2 & $1.486 \mathrm{keV} \mathrm{Al(K)} \mathrm{X-rays}$ & 0.4137 & 15.010 & 0.5233 & 3.23 & 1.2568 & Goohead, 1980 \\
\hline 3 & $4.510 \mathrm{keV}$ Ti(K) X-rays & 2.1050 & 8.534 & 0.4532 & 6.66 & 0.6188 & Goohead, 1980 \\
\hline 4 & $5.4 \mathrm{keV} \mathrm{Cr}(\mathrm{K}) \mathrm{X}$-rays & 2.6200 & 7.645 & 0.3364 & 7.55 & 0.4115 & Hiebera, 1990 \\
\hline 5 & $10 \mathrm{KVp}$ X-rays & 5.5000 & 3.500 & 0.4600 & 11.01 & 0.2576 & Lehnert, 2008 \\
\hline 6 & 25 KVp X-rays & 7.8000 & 5.800 & 0.2260 & 9.02 & 0.2097 & Lehnert, 2006 \\
\hline 7 & 29 KVp X-rays & 8.01 & 6.343 & 0.0760 & 8.57 & 0.0771 & Heyes, 2004 \\
\hline 8 & 40 kVp X-rays & 8.01 & 7.495 & 0.0780 & 7.54 & 0.09354 & Hoshi, 1988 \\
\hline 9 & $50 \mathrm{kVp}$ X-rays & 7.77 & 8.113 & 0.2580 & 6.52 & 0.3346 & Todd, 1965 \\
\hline 10 & 55 kVp X-rays & 7.59 & 8.193 & 0.2900 & 6.46 & 0.3802 & Spadinger, 1992 \\
\hline 11 & 80 kVp X-rays & 6.79 & 8.347 & 0.2700 & 6.39 & 0.3606 & Napolitanok, 1992 \\
\hline 12 & 100 kVp X-rays & 6.69 & 8.102 & 0.2390 & 6.62 & 0.3098 & Kroneberg, 1991 \\
\hline 13 & 150 kVp X-rays & 7.65 & 6.980 & 0.1900 & 7.80 & 0.2122 & Chang, 1992 \\
\hline 14 & 180 kVp X-rays & 8.98 & 6.310 & 0.1370 & 8.80 & 0.1383 & Tolkendorf, 1983 \\
\hline 15 & 200 kVp X-rays & 10.26 & 5.823 & 0.1280 & 9.61 & 0.1193 & Belli, 1989 \\
\hline 16 & 210 kVp X-rays & 11.42 & 5.590 & 0.1358 & 10.10 & 0.1215 & Hall, 1972 \\
\hline 17 & 225 kVp X-rays & 12.65 & 5.280 & 0.1015 & 10.80 & 0.0858 & Rodrriguez, 1981 \\
\hline 18 & 250 kVp X-rays & 14.68 & 4.772 & 0.1475 & 11.95 & 0.1126 & Chapman, 1971 \\
\hline
\end{tabular}


Global Journal of Engineering and Technology Advances, 2022, 10(02), 075-082

\begin{tabular}{|c|c|c|c|c|c|c|c|}
\hline 19 & $300 \mathrm{kVp}$ X-rays & 17.81 & 4.421 & 0.1280 & 12.96 & 0.0905 & Nias, 1969 \\
\hline 20 & $4 \mathrm{MV}$ X-rays & 40.00 & 2.200 & 0.1220 & 29.00 & 0.0429 & Zackrisson, 1989 \\
\hline 21 & $6 \mathrm{MV}$ x-ray & 55.00 & 1.700 & 0.1100 & 37.00 & 0.0299 & Chithrani, 2010 \\
\hline 22 & $50 \mathrm{MV}$ x-ray & 500.00 & 0.420 & 0.148 & 180.00 & 0.0099 & Zackkrisson, 1989 \\
\hline 23 & Cs-137 $\gamma$-rays & 150.70 & 0.985 & 0.2474 & 65.52 & 0.0298 & Hei, 1988 \\
\hline 24 & Co-60 $\gamma$-rays & 335.60 & 0.607 & 0.1400 & 111.10 & 0.0099 & Perris, 1986 \\
\hline 25 & $0.94 \mathrm{MeV}$ Y-90 $\beta$-rays & 508.20 & 0.531 & 0.0780 & 157.40 & 0.0066 & Barendsen, 1962 \\
\hline 26 & $4 \mathrm{MeV}$ electrons & 1947.00 & 0.287 & 0.1282 & 276.00 & 0.0059 & Haskins, 2020 \\
\hline 27 & $11 \mathrm{MeV}$ electrons & 5058.00 & 0.283 & 0.2100 & 292.50 & 0.0077 & Spadinger, 1992 \\
\hline 28 & $18 \mathrm{MeV}$ electrons & 7876.00 & 0.284 & 0.0553 & 297.50 & 0.0025 & Haskins, 2020 \\
\hline
\end{tabular}

The search for a model imply the multi-stage trials of a function $F=F(\lambda)$, provided that the semi-empirical formula fits the trend observed by the $\sigma(\lambda)$ in terms of the justifiable physical parameters $\lambda$

\section{Results and discussion}

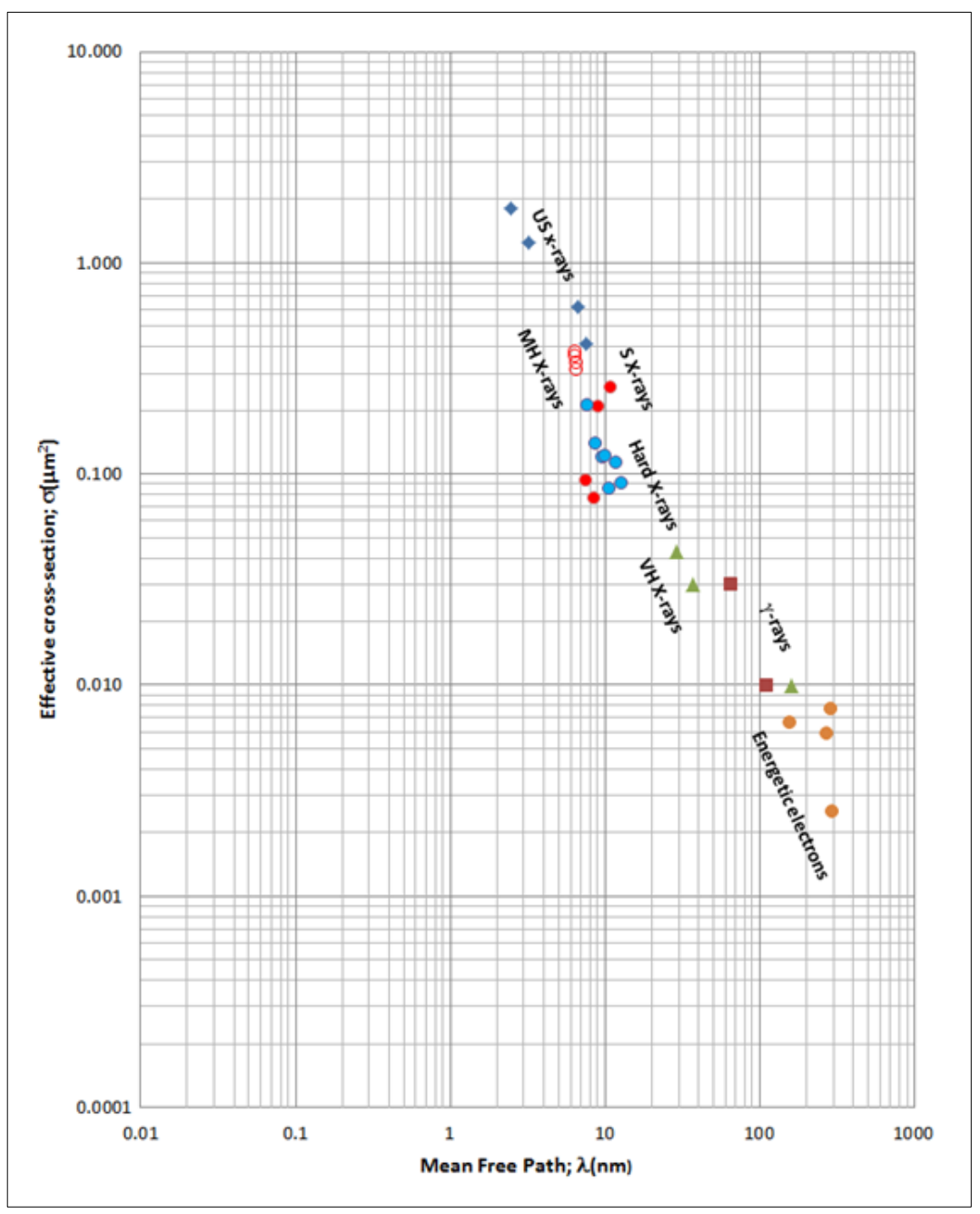

Figure 2 The effective cross section $\sigma\left(\mu \mathrm{m}^{2}\right)$ for mammalian cells vs. mean free path for primary ionization $\lambda(\mathrm{nm})$ for SIR (S; soft, US; ultra-soft, MH; medium hard, VH; very hard) 
Effective cross sections; $\sigma_{\mathrm{s}}\left(\mu \mathrm{m}^{2}\right)$ for the various mammalian cells including human, hamster cells as a function of $\lambda(\mathrm{nm})$ for SIR, as depicted in the Table-1, shown in Figure-2 in log-log scale. The meddling of inactivation cross-sections data as well as the radiation quality parameters, as seen in the Table-1 and Figure-2, is healthy. The behaviour of each class for each type of SIR data is shown in the figure. Beside that all experimental radiobiological data through the years were performed at different laboratories, the interfering is mostly due to the nature of x-rays spectrum which are produced by different anodes, filters and HV's, radiation quality parameters for different type of SIR may be interfere. High energy electrons with HV x-ray from linear accelerators are also inclusive.

Visual inspection of log-log scale, clarifies the grouping of $\sigma$ and $\lambda$ data within the spread of the physical and biological errors. Based on earlier studies by the author [43], an inflection point is expected at $\lambda_{0}=1.8 \mathrm{~nm}$, attributed to the mean chord of the strands in the DNA segment and identify that the dsb's of the DNA as the critical lesion to inactivate cells for all ionizing radiation types.

The overall shape of the relation between $\sigma$ and $\lambda$ support the idea of having unifying response of mammalian cells to SIR with an inflection point at $\lambda_{0}=1.8 \mathrm{~nm}$ which is equivalent to the interspacing distance between DNA strands. Only $C_{k}$ ultra-soft x-rays with photons of energy around $0.278 \mathrm{keV}$ can induce highest biological damage near the inflection point where $\lambda_{o}=1.8 \mathrm{~nm}$. Soft x-rays with maximum operating voltage around $40 \mathrm{KVp}$ shown next to US $\mathrm{x}$-rays, with ionization separated by $8 \mathrm{~nm}$ and lower effective cross-sections. Medium and hard $\mathrm{x}$ - rays and $\lambda$-rays, as expected have much lower cross sections due to their high energy photons and their lower ionization density. SIR like hard $\mathrm{x}$-rays, $\gamma$ rays and electrons have much smaller cross sections, as shown in Figure-2.

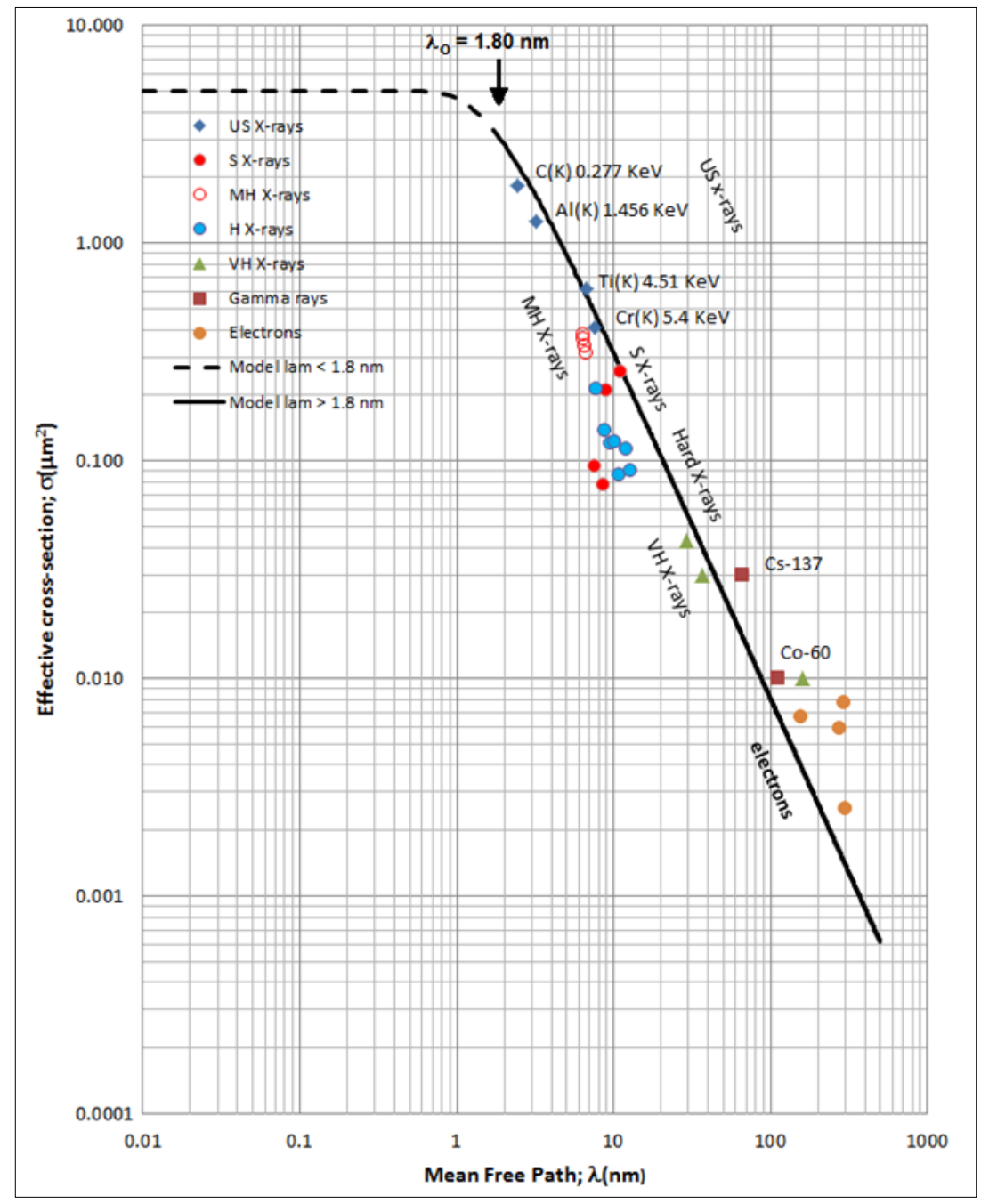

Figure 3 The unified model of radiation action on mammalian cells by SIR, manifested by $\sigma(\mu \mathrm{m} 2) \mathrm{vs}$. $\lambda(\mathrm{nm})$ as indicated by the dashed and solid curves presented

In searching of a mathematical model to manipulate this data, the following simple semi-empirical relation is used: 


$$
\sigma(\lambda)=\sigma_{0}\left(1-\exp \left(\lambda / \lambda_{0}\right)^{n}\right)
$$

Where $\sigma_{0}$ is the maximum reachable saturation cross section if ever exist, and $\lambda_{0}$ is the value of the mean free path at inflection point (the spacing between the DNA strands). The result is presented by the solid line in Figure-3.

The gradient of this linear portion in the log-log scale is $-1.59 \pm 0.06$. This part of the curve is attributed to the repairable ssb's of the DNA. The maximum damage if ever established by ultra-soft x-rays, along with water radicals' enhancement, will be around $\sigma_{\mathrm{s}}=5 \pm 0.6 \mu \mathrm{m}^{2}$

The merit of both values; the projected saturation cross section $\sigma_{0}=5 \mu \mathrm{m}^{2}$ and the mean free path $\lambda_{0}=1.8 \mathrm{~nm}($ with $\mathrm{n}=$ 1.6) indicate that the nature of this damage has got to be related to nanometric events. The scales of these events indicate that the induction of dsb's near the inflection point i.e. C (k) US x-rays is plausible. Whereas nearby soft x-rays contribute to the induction ssb's of the DNA. The crucial rule of generated water radicals in close proximity to soft $x$-rays can induce dsb's of DNA. This means soft x-rays, medium and hard $x$-rays, $\gamma$-rays or even fast electrons will never reach saturation region by their own, and the dominant interactions produced are ssb's of the DNA, in the lower region of the linear part.

\section{Conclusion}

In this work a simple model is presented. The main features of this model relies on its specification of the cellular damage in terms of biophysical parameters that relates molecular events such dsb's of the DNA to macroscopic biological effects such as cell death. In simple mathematical form; $\sigma(\lambda)=\sigma_{0}\left[1-\exp \left(-\lambda_{0} / \lambda_{0}\right)^{n}\right]$, the model indicate that the maximum damage is represented by $\sigma_{0}\left(5 \mu \mathrm{m}^{2}\right)$. In theory, the highest saturation damage leading to the death of mammalian cells should be equivalent to the geometrical cross section, $\sigma_{\mathrm{g}}\left(60 \mu \mathrm{m}^{2}\right)$. SIR can only be attributed to $1 / 12$ of the geometrical cross-section.

Further investigations are needed to indicate the rules of water radicals in cellular damage. A more sophisticated model will be vital to further demonstrate the action of ionizing radiation on mammalian cells in terms of additional radiochemical parameters related to the damaging effects by water radicals.

\section{References}

[1] Khan FM, JP Gibbons, Khan's the Physics of Radiation Therapy. $5^{\text {th }}$ ed. Philadelphia; Lippincott Williams \& Wilkins. 2014.

[2] Ding elder M, RH Ritchie, JE Turner, W Friedland, HG Paretzke, Hamm RN. Comparisons of Calculations with PARTRAC and NOREC: Transport of Electrons in Liquid Water. Radiat Res. 2008; 169(5): 584-594.

[3] ICRU Report 16, Linear Energy Transfer. Inter. Comm. on Radiat. Units and Meas. 7910, Woodmont Ave. Bethesda, MD. 20814, USA, 1970.

[4] Watt DE. A Unified System of Radiation Bio-Effectiveness and its Consequences in Practical Application. Radiation Protection Dosimetry. 1997; 70(1-4): 529-536.

[5] Hall EJ, AJ Giaccia. Radiobiology for the Radiologist. 8th ed. Philadelphia; Lippincott Williams \& Wilkins. 2018.

[6] Kellerer AM. Electron spectra and the RBE of x-rays. Radiat Res. 2002; 158: 13-22.

[7] Ward JF. DNA damage produced by ionizing radiation in mammalian cells: identities, mechanisms of formation, and reparability. Prog Nucleic Acid Res Mol Biol. 1988; 35: 95-125.

[8] Ward JF. The yield of DNA double-strand breaks produced intracellularly by ionizing radiation. Int J Radiat Biol. 1990; 57(06): 1141-1150.

[9] Iliakis G. The role of DNA double strand breaks in ionizing radiation-induced killing of Eukaryotic cells. Bioessays. 1991; 13(12): 641-648.

[10] Pouget J-P, SJ Mather. General aspects of the cellular response to low- and high-LET radiation. Euro J Nucl Med \& Molec Imag. 2004; 28(4): 541-561.

[11] Ward JF. The complexity of DNA damage- relevance to biological consequences. Int J Radiat Biol. 1994; 66: 427432 . 
[12] Katz R, B Ackerson, M Homayoonfar, SC Sharma. Inactivation of cells by heavy ion bombardment." Radiat Res. 1971; 47: 402-425.

[13] Kiefer J. On the interpretation of heavy ion survival data. In: Booz J \& HG Ebert, eds. Proceeding of the $8^{\text {th }}$ Symp. On Microdosimetry. Luxemburg: Cmm. of the Europ. Comm. 1982; 729-742.

[14] Kampf G, Eichhorn K. DNA strand breaks by different radiation qualities and relations to cell killing: Further results after the influence of $\alpha$-particles and carbon ions. Studia Biophys. 1983; 93(01): 17-26.

[15] Kramer M, G Karft. Heavy ion track structure calculations. In: Chadwick KH, Moschini G \& MN Varma. Eds. Workshop on Biophysical Modelling of Radiation Effects. Bristol: Adam Hilger. 1992; 61-68.

[16] Harder D, P Virsik-Peuckert, E Bartels. Theory of pairwise lesion interaction. In: Chadwick KH, G Moschini \& MN Varma eds. Workshop on Biophysical Modelling of Radiation Effects. Bristol: Adam Hilger. 1992; 179-184.

[17] Kellerer, AM, HH Rossi. The theory of dual radiation action. Curr. Top. Radiat. Res. Q. 1972; 8: 85-158.

[18] Watt DE, I Al-Affan, CZ Chen, GE Thomas. Identification of Biophysical Mechanisms of Damage by Ionizing Radiation. Radiat. Prot. Dosim. 1985; 13: 285-294.

[19] Goodhead DT, J Thacker, R Cox, RE Wilkinson. Effectiveness of $0.3 \mathrm{keV}$ carbon ultrasoft x-rays for the inactivation and mutation of cultured mammalian cells. Int J Radiat Biol Relat Stud Phys Chem Med. 1979; 36(2): $101-114$.

[20] Hieber L, K Trutschler, J Smida, M Wachsmann, G Ponsel, AM Kellerer. Radiation-induced cell transformation: Transformation efficiencies of different types of ionizing radiation and molecular changes in radiation transformation and tumor cell lines. Environ Health Presp. 1990; 88: 169-174.

[21] Lehnert A, E Lessmann, J Pawelke, W Dörr. RBE of $25 \mathrm{kV}$ x-rays for the survival and induction of micronuclei in the human mammary epithelial cell line MCF-12A. Radiat Environ. Biophys. 2006; 45: 253-260.

[22] Lehnert A, E Lessmann, J Pawelke, W Dörr. RBE of $10 \mathrm{kV}$ x rays determined for the human mammary epithelial cell line MCF-12A. Radiat Res. 2008; 169(3): 330-336.

[23] Heyes GJ, AJ Mill. The neoplastic transformation potential of mammography x-rays and atomic bomb spectrum radiation. Radiat. Res. 2004; 162(2): 120-127.

[24] Hoshi M, S Antoku, N Nakamura, W Russell, R Miller, S Sawada, M Mizuno, S Nishio. Soft X-ray dosimetry and RBE for Survival of Chinese Hamster V79 cells Int J Radiat Biol. 1988; 54(4): 577-591.

[25] Todd PW. Heavy-ion irradiation of cultured human cells. Radiat. Res. 1967; 7: 196-207.

[26] Spadinger I, B Palci. The relative biological effectiveness of ${ }^{60} \mathrm{Co} \gamma$-rays, $55 \mathrm{kVp}$ x-rays, $250 \mathrm{kVp}$ x-rays, and $11 \mathrm{MeV}$ electrons at low doses. Int J Radiat Biol. 1992; 61(3): 345-353.

[27] Napolitano M, M Durante, G Grossi, M Pugliese \& G Gialanella. Inactivation of C3H 10T1/2 cells by monoenergetic high-LET $\alpha$-particles. Int J Radiat Biol. 1992; 61(6): 813-820.

[28] Kronenberg A. Perspectives on fast-neutron mutagenesis of Human Lymphoblastoid cells. Radiat Res Suppl. The international colloquium on neutron radiation biology.1991; 128(1): S87-S93.

[29] Chang PY, CA Tobias, EA Blakely. Protein synthesis modulates the biological effectiveness of the combined action of hyperthermia and high-LET radiation. Radiat Res. 1992; 129(3): 272-280.

[30] Tolkendorf, E, K Eichohorn. Effect of ionizing radiation of different linear energy transfer of the induction of cellular death and of chromosome aberrations in cells of the Chinese hamster. Studia Biophys. 1983; 95 : 43-56.

[31] Belli M, R Cherubini, S Finotto, G Moschini, O Sapora, G Simone, MA Tabocchini. RBE-LET relationship for the survival of V79 cells irradiated with low energy protons. Int J Radiat Biol. 1989; 55(1): 93-104.

[32] Hall EJ, W Gross, RF Dvorak, AM Kellerer, HH Rossi. Survival curves and age response functions for Chinese hamster cells exposed to x-rays or high LET $\alpha$-Particles. Radiat Res. 1972; 52(1): 88-98.

[33] Rodriguez A, EL Alpen. Cell survival in spheroids irradiated with heavy-ion beams. Radiat Res. 1981; 85(1): 2437.

[34] Chapman JD, RG Webb, J Borsa. Radiosensitization of mammalian cells by p-nitroacetophenone; I. Characterization in asynchronous and synchronous populations. Int J Radiat Biol Relat Stud Phys Chem Med. 1971; 19(6): 561-573. 
[35] Nias AH, D Greene, M Fox, RL Thomas. Effect of $14 \mathrm{MeV}$ monoenergetic neutrons on HeLa and P388F cells in vitro. Int J Radiat Biol Relat Stud Phys Chem Med. 1968; 13(5): 449-456.

[36] Zackkrisson B, B Johansson, P Östbergh. Relative biological effectiveness and Oxygen enhancement ratio of 50 Mv X-Rays, Acta Oncologica. 1989; 28(4): 529-535.

[37] Chithrani DB, S Jelveh, F Jalali, M van Prooijen, C Allen, RG Bristow, RP Hill, DA Jaffray. Gold nanoparticles as radiation sensitizers in cancer therapy. Radiat Res. 2010; 173: 719-728.

[38] Hei TK, DJ Chen, DJ Brenner, EJ Hall. Mutation induction by charged particles of defined linear energy transfer. Carcinogenesis. 1988; 9: 1233-1236.

[39] Perris A, P Pialoglou, AA Katsanos, EG Sideris. Biological effectiveness of low energy Protons. I. Survival of Chinese Hamster Cells. Int J Radiat Biol Relat Stud Phys Chem Med. 1986; 50(6): 1093-1101.

[40] Barendsen GW. Dose-survival curves of Human cells in tissue culture irradiated with $\alpha-, \beta-$, and $20-\mathrm{KV}$. X- and 200-KV. X-radiation, Nature. 1962; 193: 1153-1155.

[41] Haskins JS, SK Martinez, M Engstrom, M Murakami, T Mori, D Leary, TA Kato. Electron scattering in conventional cell flask experiments and dose distribution dependency. Scientific Reports. 2020; 10(1): 482-490.

[42] Watt DE. Quantities for Dosimetry of Ionizing Radiation in Liquid Water. London, Taylor and Francis. 1996.

[43] Watt DE, AS Alkharam. Charged particle track structure parameters for application in Radiation Biology and Radiation Chemistry. Int. J. Quantum Chem. 1994; 52(S21): 195- 207. 